\title{
A Visual Epistemology of Readymade
}

\author{
Christophe Schinckus \\ Taylor's University, Malaysia
}

\begin{abstract}
The enunciation of the words "All" "Ready" "Made" auditory forms the adverb "Already" that actually defines the essence of a readymade. This article presents several intertextual recontextualisations of this notion are proposed through a renarrativization of readymade (wordy) components. This collection has no other intention that unloading the concept of readymade by using art to think about art and acknowledging therefore the art's capacity for self-reflection and autotheorizing in line with recent call for the development of an artistic research.
\end{abstract}

Keywords: Readymade, Enunciation, Duchamp, Differance

Many eminent artists (e.g., Rodin, Warhol, Duchamp) has used their art to elicit responses, and in particular responses asking about the nature of art. The idea of Readymade objects has played a significant role in this journey. The term 'Readymade' was first used in English in the translation (1911) of Henri Bergson's 1900 essay on comedy "le rire: essai sur la significance du comique". Duchamp used this word to make a revolution in art (Mascheck, 1975). Deriving from Rodin's perspective that every subject is worth being represented, readymades refer to common objects that have been elevated to the status of art by the artist.
Duchamp's approach to aesthetic is relational where the readymade is presented as a rendez-vous (De Duve, 1989, 1991). Duchamp explicitly acknowledged this aspect by inscribing the date, hour, minute, and the title of his readymades as information. In this temporal perspective, Duchamp made a judgement of taste and declared: this is art at this time. The concept of readymade is still undefined and generates a quite a few debates. Consider this:

"The Readymades are not anti-art... but rather "an-artistic". Neither art nor anti-art, 
but something in between, indifferent, existing in a void... Their interest is not plastic but critical or philosophical. It would be senseless to argue about their beauty or ugliness, firstly because they are beyond beauty and ugliness, and secondly because they are not creations but signs, questioning or negating the act of creation" (Paz, 1993 cited from De Duve, 1993, p.164).

Duchamp wanted to show that art is not different from anything else in the world, setting the stage for anti-art artists, such as Warhol and conceptual art. Indeed, by elevating the common and the everyday aspect to art, Duchamp challenged the definition of art and what is institutionally accepted as art in the galleries. Consequently, now that anything can be art, nothing is art (Schinckus, 2018). Readymades have no style, they rather embody the absence of style as a specific style. Their aesthetic is totally ignored - they exist in their symbolic and enunciative function. This article explores the second function.

For Duchamp, a readymade involves an enunciative relationship between the artist's choice and the interpretation of the spectator in particular creative act, as he explained,

"The creative act takes another aspect when the spectator experiences the phenomenon of transmutation: through the change from inert matter into a work of art, an actual transubstantiation has taken place, and the role of the spectator is to determine the weight of the work on the aesthetic scale. All in all, the creative act is not performed by the artist alone; the spectator brings the work in contact with the external work by deciphering and interpreting its inner qualifications and thus adds his contribution to the creative act" (Duchamp (1957, p.29).

The artist's way of choosing is not an aesthetic choice, as it is based on visual indifference and/or on the absence of taste - it is rather a conceptual process. In this way, Duchamp dismissed the category of taste when the choice of the readymade was done (de Duve, 1991). It is necessary and sufficient for the artist and the object to exist and to be able to meet. The object is given, it exists somewhere, no matter where, and is mentally available. By emphasising the importance of choice, Duchamp inaugurated what von Hantelman (2011) called 'the curatorial paradigm' arguing that in the field of art, it was Duchamp who anticipated paradigmatically a new archetype of creativity. In her view, it was his choice (which is what she considers curatorial) that allowed the readymade to mark the transition of a production oriented society to a selection oriented society. "Duchamp arguably made curational tasks a veritable lifework and the pivotal catalyst through which to understand and expose the artwork as such [...] The invention of the readymade needed to be curated; in other words, it required a public exhibition" (Filipovic, 2013).

In this new relational perspective of thinking art, objects and authors are nothing but the conditions of their encounter, and nothing further being supposed about them. The first condition to have the readymade is to choose and specify the readymade.

\section{The enunciative paradigm}

Only a choice and an enunciation of a readymade is sufficient to create a piece of art. The most ironic situation is the fact that this rendez-vous between the artist and observers often takes the form of a marketable commodity (example, a snow shovel or an urinary) that become art through its enunciation. Basically, enunciation refers to the act of pronouncing a word. The genius of Duchamp is to use the enunciation as a medium in art pioneering therefore conceptual arts. In this context, the way of detonating an common object can transform it into a piece of art. Such situation generates a new room for a large number of potential marketable ready-made: all persons with skills for enunciation of a particular 
choice might be recognised as an artist and therefore sell her/his works on the market.

This article aims at experiencing this enunciative nature of readymade by presenting a visual collection exploring the auditory enunciation that derives from changing the semiotics of the works while retaining the sound of their word to emphasise the richness of the readymade praxis in art. Precisely, seventeen visual essays will be presented; all of them exemplifying a potential distortion of the conventional auditory enunciation of the words "All" "Ready" "Made". The conjunction of these three words auditory forms the adverb "Already" that actually defines the essence of a readymade. I acknowledge the explorative nature of this article that actually can be seen as an essay articulating my thoughts on the epistemology of Duchampean readymades. In this perspective, the objective of this paper is not to demonstrate beyond reasonable doubt but rather to suggest a plausible analysis through a disciplined imagination of these visual artefacts that are labelled 'Readymades'.

Several intertextual recontextualisations of this notion are proposed through a re-narrativization of readymade (wordy) components. This collection has no other intention that unloading the concept of readymade. The term already is used in English to emphasise that something was completed or achieved before something else happened. This adverb characterizes very well the idea of the readymade justifying the reason for why I associated these three terms in this article. In this collection, the idea of readymade is presented as an intentional category whose enunciative nature echoes to a creative alignment with the replicant-theory observed in science. So doing, the epistemic nature of readymade that, since its invention by Duchamps questions artistic practices is explicitly emphasised. In this visual epistemology of readymade, I implicitly played a "mediumistic role" (Naumann, 1993, p.41) of curator by presenting a systematic composition of objects proposing, "an euretics and a mnemotechnics invoke a model of pro-active mimesis, in which the enunciative functions of the readymade and copying without copying are defended as transformative acts, and as such underline the convergence of recombinant practice with network thinking across a number of practices and disciplines"(Robert, 2007, p.182).

The selection of these readymades in combination with the formulation of their names were actually the most important step. As Harriet and Sidney (1951, p.310) wrote it,
"Ready-mades are what the name implies, complete objects which are at hand, and which by reason of the artist's selectivity are considered by him as belonging in the realm of his own creativity. The assumption is that the object, conveying properties which coincide with the artist's angle of approach, is endowed as a work of art by virtue of the insight and authority of the artist's selection. Selection is here no longer just a step in the process. It becomes a completed technique".

A readymade is an imitation aiming at creating a tension with the same - it is an imitating metaphorical reconstruction of the same. All readymades are a reproduction of themselves. Reproduction becomes a form of reenactment through a particular enunciation. Duve (1995) identified four conditions to have a enunciaiton: 1) a referent (content of the enunciation); 2) an emitter (someone to enunciate); 3) a receiver (someone to read/hear) and 4) a place where the enunciation makes sense. Readymades actually meet all these four conditions leading de Duve (1995) to conclude that a readymade is a piece of art that has been reduced to its enunciation. In this perspective, works are not considered for their content or their aesthetic value but rather for their enunciation. This visual article explores this aspect by proposing a collection of works whose major outcome is in the declination (title) of all these components, inviting 
people literally to see the importance of language in this key concept of contemporary art. Readymades are art about art, they refer to art practices without being auto-referential since these replicated readymades actually indicate the existence, as selected objects, of the work to which they refer. Readymades are autoreferential artefact of art opening doors to reflect on art. This paper emphasises the capacity of art for selfreflection and auto-theorizing. The following section presents the collection of visual essays exemplifying the enunciative nature of readymades.

\section{Collection of Readymades}

This section offers 17 pictures of existing objects selected or assembled by the author to exemplify the enunciative nature of readymades. In this context, the collection consists in presenting unassisted and rectified readymades where simple/cheap objects are repossessed through a particular narrative. Unassisted readymades can actually be seen as "minor detourmement" drawing their meaning form a new context in which they have been placed while rectified readymades echoes to a more "deceiptive detournement" in which a particular element (in addition to a new context) creates the meaning for the readymade. All these objects have been selected for their ability to be formulated on a particular enunciation related to their status or materiality. Therefore, the process used for the selection of these readymades refers to the famous Duchamp's play on words for one of his work entitled l'impossibilité $d u$ fer (impossibility doing art) where the artist played with the materiality of the readymade to suggest enunciatively something different. Interestingly, an enunciation is not an object neither a concept. There is nothing to see or to understand, just a repetition of a formulation ('Already made") that takes several visuals forms. This repetition of the tension between the objects and their formulation implicitly refers to an infinite potential recontextualization since all these alliterations always multiply by differentiating them. The way of addressing the topic of readymade does not refer a particular representation or an isomorphism but rather to a way in which the verbal components interact with their materiality.

\section{All readymades: Reciprocal replicates}

The first picture actually shows two phenomenological appearance of two famous unassisted readymades physically exhibited in a room with a picture of these two Duchampian works. On the right, one can find a canvas on which two definitions of a readymade are given: "readymades are ordinary manufactured objects that the artist selected and modified, as an antidote to what he called 'retinal art' (Tomkins, 2014 , p.158) and "this is an ordinary object elevated to the dignity of a work of art by the mere choice of an artist" (Breton 1938, p.81). The role of this first piece is importance since it literally to set the scene of the project by informing observers what a readymade is. Replicas of these famous readymades are actually used here as readymades.

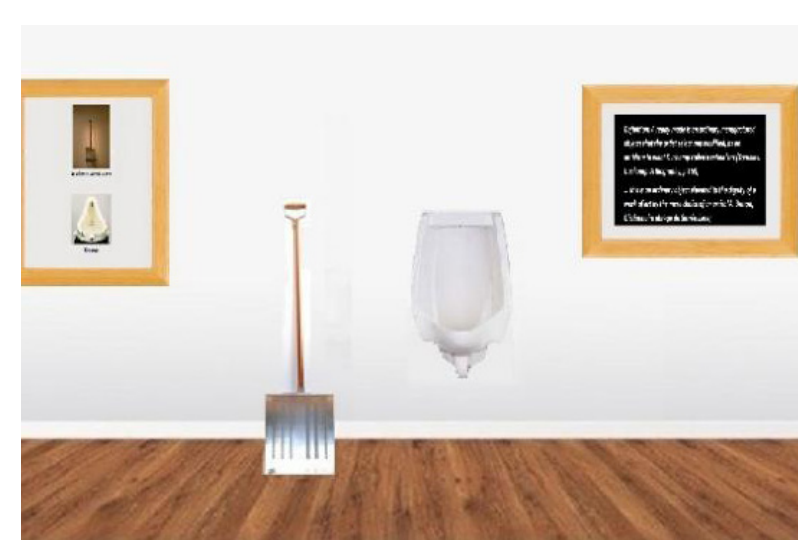

Figure 1: Reciprocal replicates

\section{Already-Made: In advance of the split pea}

The second work is an appearance echoing to another well-known readymande (In advance of the broken 
arm - En attendant le bras casse in French). Through its visual exhibition but also through its title "In advance of the split pea" (En attendant le pois casse in French), this unassisted readymade evokes the well-known snow shovel that Duchamp used as a

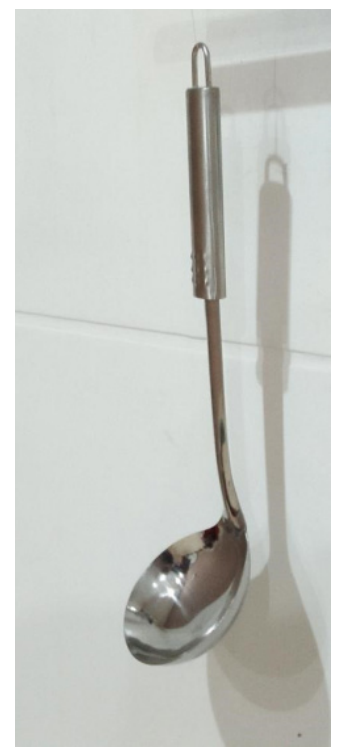
readymade. This second image exemplifies the semantic space of "Already made" associated with the concept of readymade. By definition, a readymade refers to something that has been already made/ manufactured/produced. This something is here another readymade.

Figure 2:

In advance of the split pea

\section{Hall Ready-Made: Who extinguishes destroys}

The third work refers toa common object (extinguisher) that can be associated with an unassisted readymade to exemplify a specific case of its enunciation: Hall ready-made. This association of readymade with

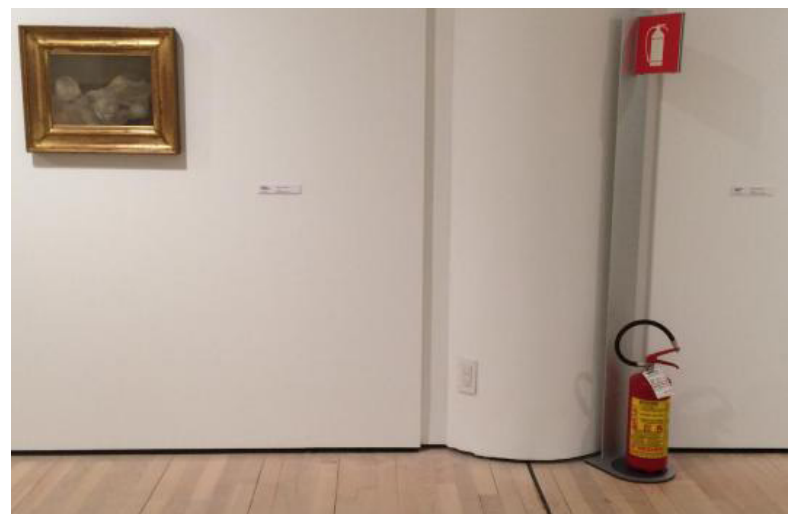

Figure 3: Who extinguishes destroys
Hall makes sense in a Duchampian way of justifying the object as a piece of art - a gallery or a museum (taking here the form of a hall) is required to elevate a common object to a piece of art. The presence of the canvas on the wall (in a hall) of this gallery testifies the institutional condition to recognise this object as a piece of art and the same is true for all common elements present in an art gallery/museum - the only difference refers to the way of attracting the eyes of the observers. This work is close to Lavier's work (Sicli NC2 - 1992) which showed a rectified readymade by exhibiting a painted extinguisher. The title of this work echoes to an artistic statement according to which all creative fires that are extinguished actually embody missed opportunities.

\section{All reedy made: Who paints without air milks a cow in a basket}

The fourth unassisted readymade is a physical expression of its enunciation: all components of this object are made in the same material: reed. Such object emphasises the importance of artistic labour through the operative hand that actually produced this basket. This readymade proposes a dialectic tension between the decomposition of labour skills required to produce this object and the artistic skills related to the choice of the artistic. In this Duchampian vision, craft and art become one in their reproductibility. This readymade illustrate a transportation from a productive sphere to another (cultural) sphere.

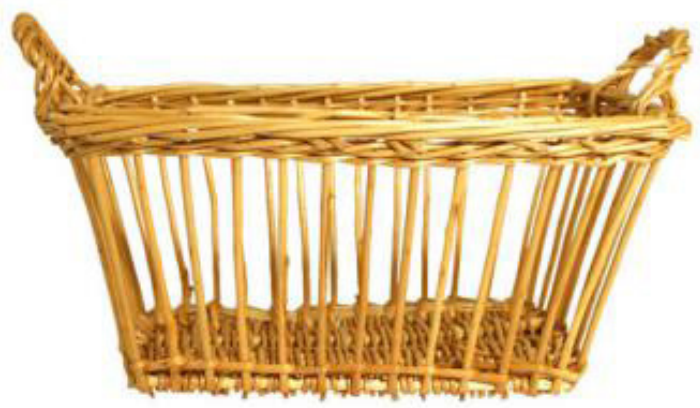

Figure 4: Who paints without air milks a cow in a basket 


\section{Hall reedy made: Unseating the loveseat of readymades is the reedy seat of my mad head - summer thought}

The fifth work shows a rectified readymade taking the form of a hall with all walls made in reed material. Such picture allows the observers to see a visual configuration whose description evokes the nature of a readymade: "already made".

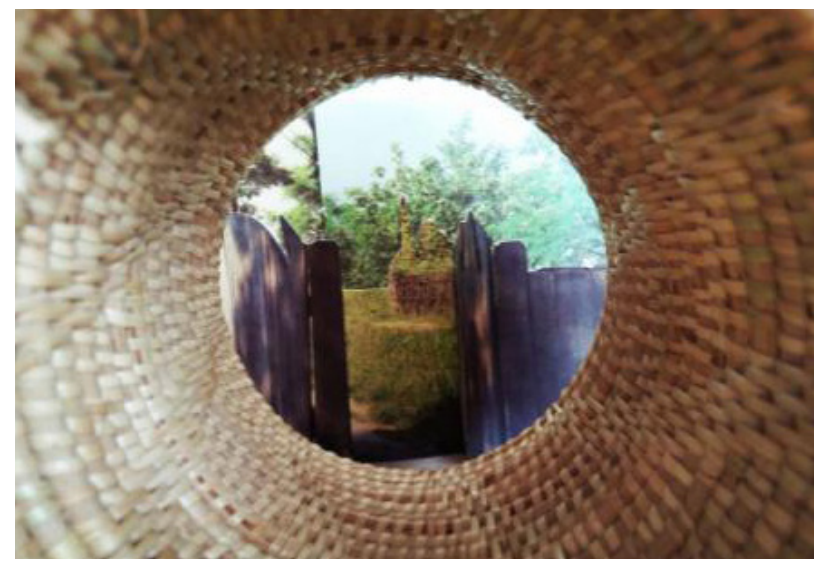

Figure 5: Unseating the loveseat of readymades is the reedy seat of my mad head - summer thought

\section{All ready maid: Cover-Maid}

This sixth illustration is another unassisted readymade composed by two elements that usually are part of a maid outfit. These objects have been selected for the auditory familiarity between the terms "maid" and "made". This work also echoes to the artistic labour by suggesting that what is done with this outfit can actually be associated with art. Moreover, the word readymade is usually associated with clothing and, Duchamp actually used this aspect when he created his Pair of Aprons (1959). This readymade combines the wordy component of "maid" (pronounced as "made") with the reference to an existing readaymade composed by aprons.

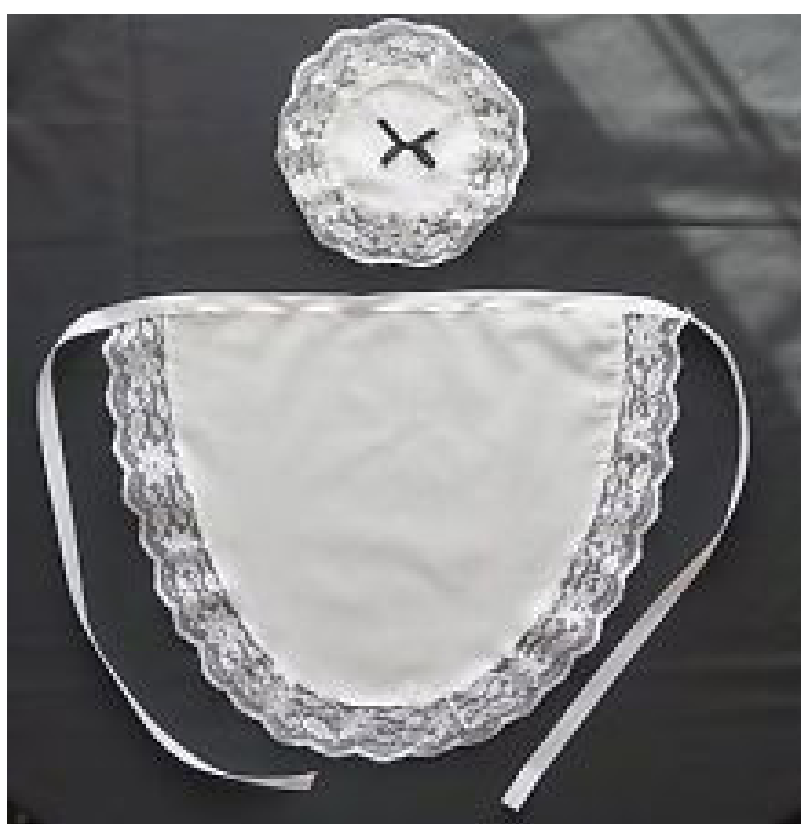

Figure 6: Cover-Maid

\section{All reedy maid: Wall Whisker}

This piece of work simply exhibits three reedy sweepers. I kept here the theme of "maid" its auditory familiarity with the word 'made. The next step was therefore to find an object made in reed that could explicitly refer to a maid. The key element of this readymade is its materiality whose wall-hug presentation also evokes indirectly the Duchamp's shovel.

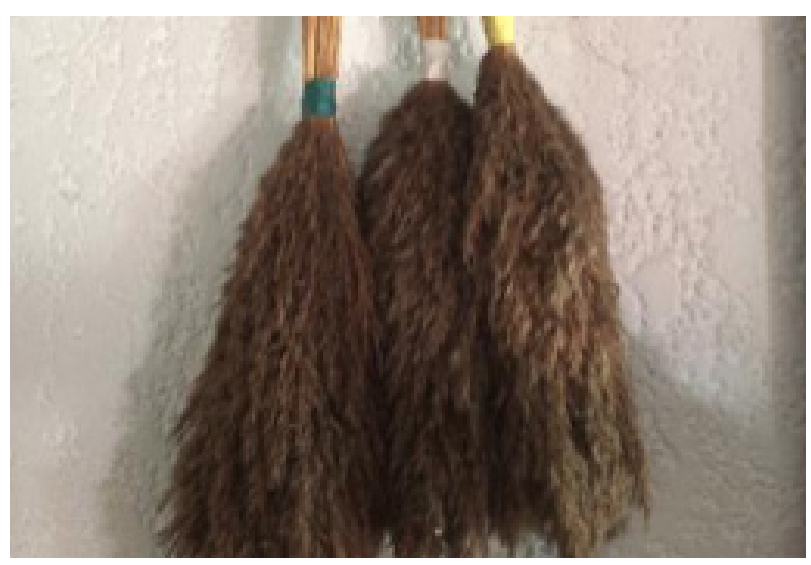

Figure 7: Wall Whisker 


\section{Hall ready maid: Crowded Objects}

This picture extends the auditory themes evoked earlier by presenting a different form of the enunciation. The illustration shows a hall with usual tools and devices ready to be used by a maid. This image shows another semantic variation of an unassisted readymade.

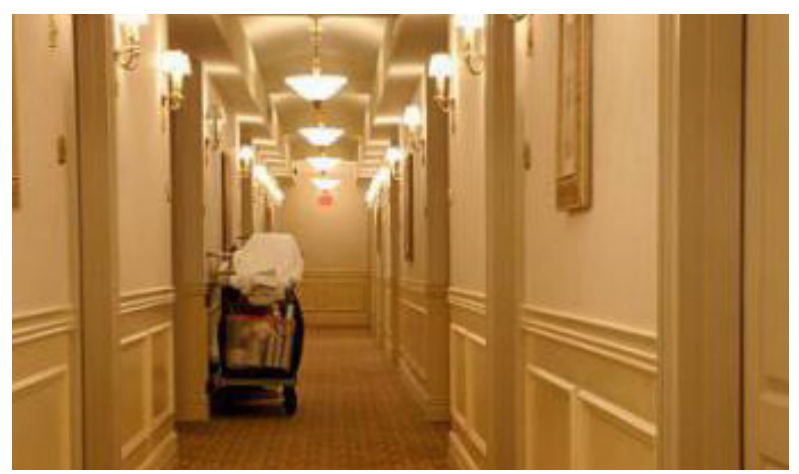

Figure 8: Crowded Objects

\section{All read email: Mail Made Mad}

This work proposes a new semantic area combining the enunciation of "all", "read" with "email" to explore another aspect of readymade. Precisely, this picture shows rectified readymades composed by several already made ingredients: a printing of emails and a collage depicting famous faces of painting. Beyond the implicit reference to the Duchamp's LHOOQ, this work also extends the notion of readymade to the mass production of personal information (emails).

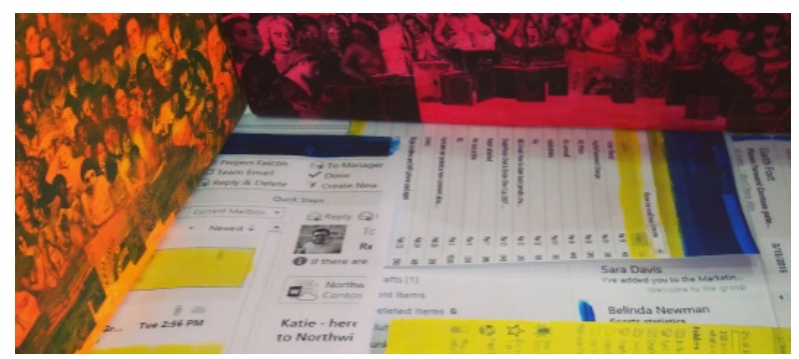

Figure 9: Mail Made Mad

\section{Hall reed email: Walls read info}

This work literally depicts its enunciation: a situation evoking a hall made in reed ending on an email. Because the last word of this new theme does not end by the letters " $\mathrm{d}$ " or "de" as all others works previously presented, this specific case is a boundary case of the semantic space offered by the "already made" theme. The configuration of this piece is an enunciative composition to extend the previous work by associating information and emails to readymade.

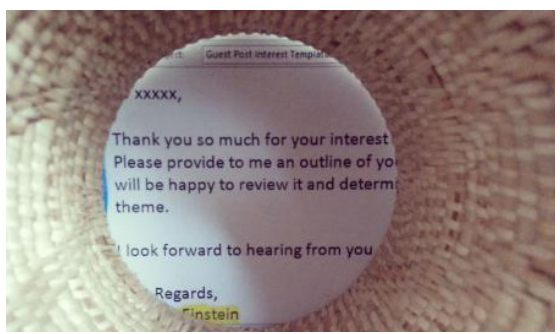

Figure 10:

Walls read info

\section{Aul reedy made: Reedy Heart}

Aul is a rustic character made by a composition of several reedy elements assembled with glue. This reedy presence is actually an original work since it is the only one that explicitly evokes a name/firstname. Such perspective therefore associates semantic sphere of rectified readymade to linguistic terms nominating people.

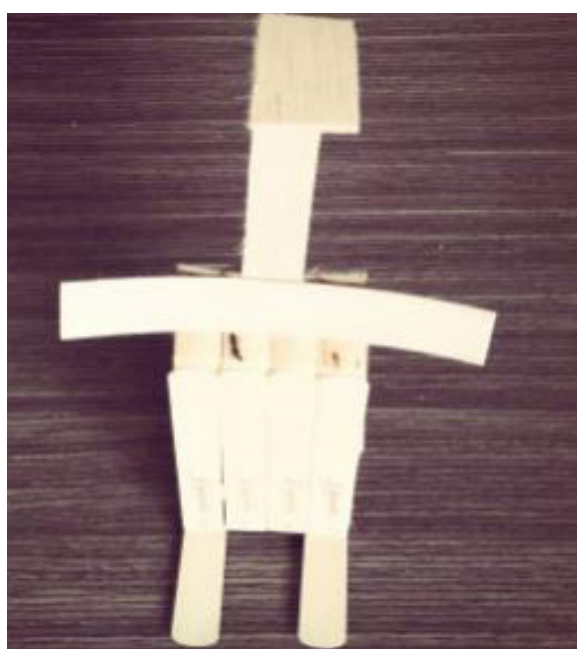

Figure 9: Mail Made Mad 


\section{Hole ready made: Electrical Nares}

The two wall outlets embody the idea of readymade by illustrating an additional semantic variation. Precisely, the enunciation of these unassisted readymades brings three words ('Hole'; 'Ready'; 'Made') together to suggest another enunciation of the key theme of this essay (Already made).

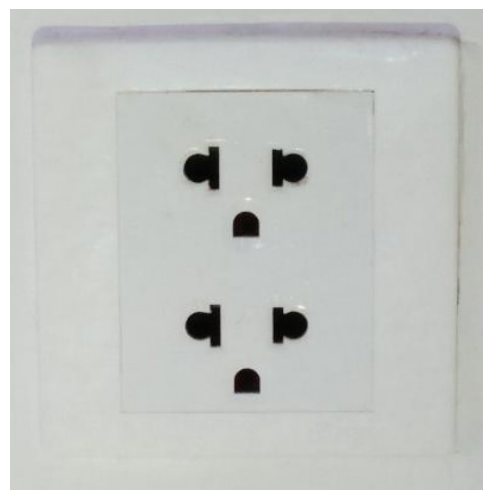

Figure 12:

Electrical Nares

\section{Hole reedy made: \\ Ready art and reciprocally...}

This unassisted readymade exemplifies the idea of a hole made in reedy made object. A flute made in reed is probably the best telling example of such item whose pronunciation indirectly echoes to the idea of "already made".

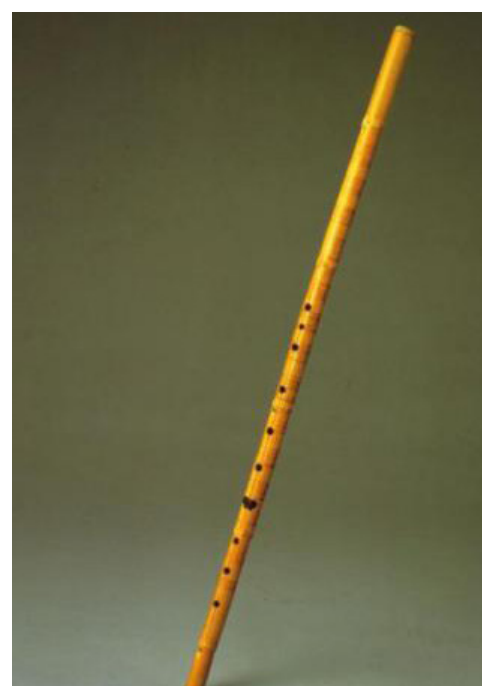

Figure 13:

Ready art and reciprocally..

\section{Hole ready maid:}

\section{The rise of readymade is the sink of art}

This work shows an unassisted readymade selected, on the one hand, for its relationship with the thematic of the "maid" (illustrated by the sponge and the sink) and, on the other hand, for the direct reference to the idea of "hole" whose enunciation echoes to 'all'. Again the complete pronunciation explicitly refers to the Dumchampian theme of Already made.

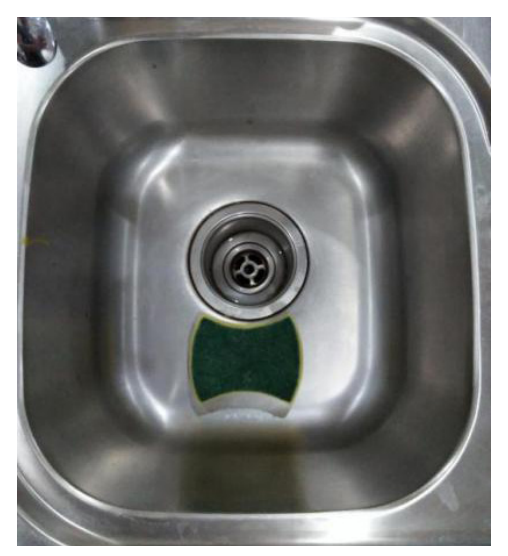

Figure 14:

The rise of

readymade is the

sink of art

\section{Hole reedy maid: Tousled Alterity}

For this work, I kept the theme of the maid that I combined with the words 'hole' and 'reedy' to form the term already made. Visually, this combination

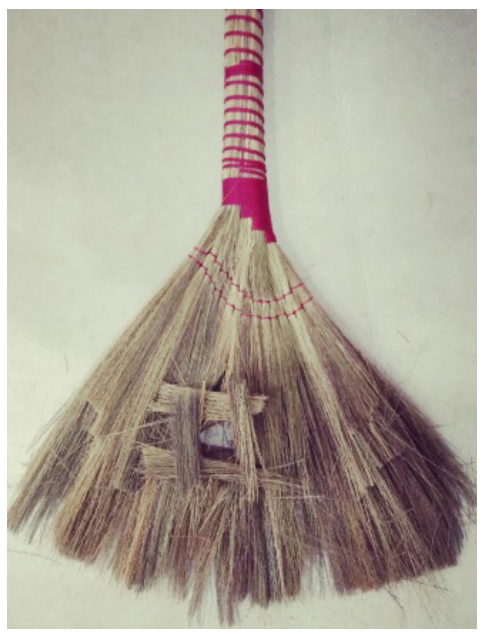

Figure 15:

Tousled Alterity 
consists in a rectified readymade exhibiting a maid sweeper in which a hole has been made. Such work visually embodies its enunciation (already made).

\section{Hole read email: Try to ESC ape}

As the title suggests it, this work illustrates a specific enunciation of the readymade. Like previous works mentioned above, this work exemplifies a boundary case of readymade focusing on the visualization of the enunciation: the ability to read an email through a hole. The visual presentation of this readymade echoes to The Green Ray, a readymade that Duchamp exhibited in 1947 during an exhibition dedicated to Surrealism in Paris.

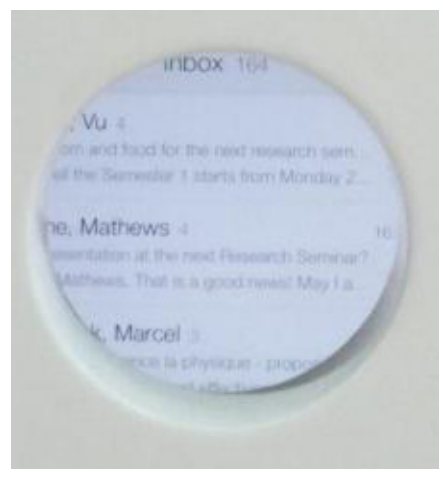

Figure 16:

Try to ESC ape

\section{Hole reed email: Escape the Trial}

Due to its auditory familiarity with the previous readymade, this work is visually similar to the previous

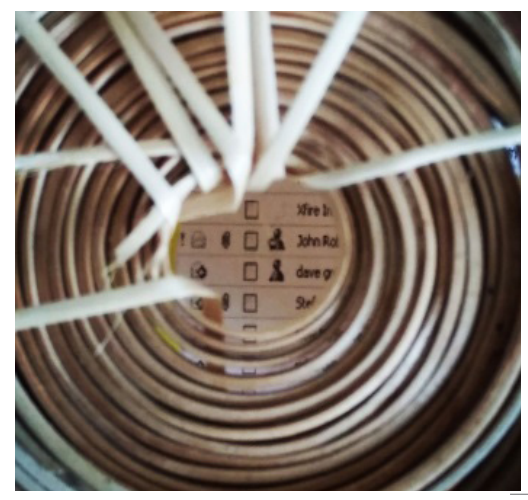

Figure 17: one entitled "Hall reed email". In the same vein, this readymade shows a hole made (by reedy component) through which on can see the existence of an email exemplyfing the enunciation of the work.

\section{Readymades \& social semiotics}

The previous section exhibited a combination of objects chosen for their materiality and their auditory ability to echo to the words "already" "made". In other terms, the selection of these particular materials has been proposed in accordance with a pre-existing social system of art in which the association of these words "already" and "made" carries a particular meaning. In this perspective, art refers to a particular social context in which viewers, participants, artists, and curators are all part of a more complex dialectic network. The existence of such social context is actually the necessary condition for conveying a meaning to the collection of heterogeneous objects presented in the previous section. Precisely, as Danto (2013) emphasized it, there is a cultural art world that has defined the meaning of what is a readymade through a specific narrative in art theory. In other words, there is first a 'seeing-as' that confers on an art work its status as artwork. Theory ensures that readymades can be seen as artwork through a complex conventionalized relationship between the artist and the viewers. This complex inter-relationship between the individuals (viewers, artists, curators), the image, the object and the meaning as part of culture refers to social semiotics.

The meaning given to images or art works is actually defined by cultural convention. Readymades become part of these artistic conventions as well as the exhibition in which these objects are shown. Precisely, an exhibition can be perceived as a readymade since it combines a collection of already existing art works (objects) and it can also be used as an artistic 
medium on its own. In this context, readymades and exhibitions share the common feature of resulting from a selection-oriented process. This transition between a production-oriented art and selectionoriented one has been emphasized by Duchamp who, as we mentioned earlier, inaugurated the 'curatorial paradigm' in which exhibitions are means of interrogation. As mentioned by Filipovic, (2013, p.22), "Artist-curated exhibitions have for too long lingered in an historical no man's land despite the fact that they have been vital to the development of artists' thinking and practices". Exhibit means to expose, to show, to inform. The complex relationship between the exhibition and the audience refers to something that could help the latter to give a meaning - exhibition is a way of making someone aware of something. In this context, exhibition became a way of communicating and a way of experiencing the notion of readymade since, like the exhibited Duchampian readymades, the exhibition presents a collection of already made artworks. By exhibiting a collection of readymads, this article also materializes the necessary conditions of the readymade: to being exhibited (Filipovic, 2013) and to be enunciated (de Duve, 1989).

This paper offers a visual and verbal understanding of the enunciative nature of readymade as major element of their social meaning. My collection of readymades interestingly combines two levels of meanings: a first one related to their names in line with their materiality; and a second one referring to their status of readymade. In 1956, Debord (1956) introduced what he called a minor and a major detournement. While the first refers to "an element which has no importance in itself and which thus draws all its meaning from the new context in which it has been placed" (Debord \& Wolman, 1956, p.8); the latter rather corresponds to "the detournement of an intrinsically significant element which derives a different scope from the new context" (Debord and Wolman, 1956, 1956, p.8). My collection of unassisted and rectified readymades respectively echoes to a minor and a major detournement whose enunciative distortion generates a demythologization of the art work by extending its scope to words. Such initiative actually paves the way to the possibility to consider the readymade as an involuntary imaginary space suggested by their enuciative nature. This perspective actually emphasizes the non-saturation of the concept since all our readymades could be presented through a different assemblage renouncing therefore to all eternity value or uniqueness. On this point, Duchamp (1961, p.141) explicitly mentioned, "Another aspect of the readymade is its lack of uniquess - the replica of a readymade delivering the same message" - that is actually the message of my collection of readymade. All visual and enunciative games around the idea of readymades take the form of wordy and material replica of readymades that illustrate the ambiguous nature of creation. The reality of a readymade is not in its physical expression but rather in its possibility to be a replica of something else and its own signifier. In other words, a readymade appears to be a philosophical speculation on the epistemological nature of objects that function as semiotic elements.

\section{Conclusion}

This article presents the concept of readymade as a specific genre that crossed the usual borders between the visual and the textual sphere. All repetitions of readymade do not alter its "conceptuality" - all replicas of a readymade still refers to its conceptual expression. This article is an explorative work on the textual dimension of readymade. Combining wordy components (selected on the basis of the materiality of the readymade) with direct and indirect references to existing Duchampian readymade, this article extends the notion of readymade to words. Precisely, words and languages define everyday detournements that are use and re-use every single day. The collection of works presented above are intended to be 'to the hear' indistinguishable. In other terms, the enunciation of these works echoes to their 'sameness' but their writing and their visual contextualization refers to something 
different. This idea of sameness in a repeated difference can be related to the notion of 'Differance' developed by Derrida (1978), Precisely, all these readymades belong to what is recognized as present here and now that can persist as the same (readymade) through their repetitions involved different interpretative contexts. This paper exemplifies the movement that produces the conditions of possibility of diverse lexical apparitions of the same conceptual identity: the Duchampean readymade. By illustrating the gap between the narrative (writing) of the readymades title and their enunciation (langue), this article paves the way to further research on an analysis of readymades through the Derridean lens of Differance.

This article also exemplifies the so-called curational paradigm that is often associated with Duchamp. "What post-conceptual artists do technically and what curators do technically - the organization, manipulation and re-narrativization of readymade components become interchangeable" (Robert, 2007, p.186). Because readymades presented here can be assembled differently, they renounce to all eternity value and offer a potential infinite re-work. In other words, in line with the idea of readymade, there is a lack of uniqueness and all replicas of readymade deliver the same message than a readymade.

In conclusion, this work offers a visual reflection on the epistemological status of readymade. In doing so, I use art to think about art acknowledging therefore the art's capacity for self-reflection and auto-theorizing in line with the call for artistic research written by Busch (2009) or Cazeaux (2017).

\section{References}

Breton A. and Eluard P. (eds) (1938), Dictionnaire abrégé du surréalisme, Paris: Galérie Beaux-Arts.

Busch K. (2009), "Artistic Research and the poetics of knowledge", Art and Research: A Journal of Ideas, Contexts and Methods, vol 2, no2, p.1-7.
Cazeaux C. (2017), Art, Research and Philosophy, London: Routledge.

Danto A. (2013), What Art Is, New Haven \& London, Yale University Press.

Debord G. and Wolman G. (1956), "A User's Guide to Détournement", Les Lèvres Nues, vol.8 (May).

De Duve Th. (1989), Au nom de l'art. Pour une archéologie de la modernité, Paris: Minuit.

De Duve Th. (1991), Pictorial Nominalism; On Marcel Duchamp's Passage from Painting to the Readymade, Minneapolis: University of Minnesota Press.

Derrida J. (1978), Writing and Difference, London: Routledge.

Duchamp M. (1957) - p.29, "The Creative Act”, ARTNews, vol 56, no 4 .

Duchamp (1961), Apropos of Ready Mades, 1961' (Duchamp's lecture at the MOMA museum), New York, 19 October 1961; in Art and Artists 1, July 1966: 47.

Filipovic E. (ed.) (2013), When Exhibitions become form: on the history of the artist as curator, Brussels WIELS Contemporary Art Centre.

Harriet J. and Sidney J. "Marcel Duchamp: Antiartist" in Motherwell R. (ed.), The Dada Painters and Poets: An Anthology, New York: George Wittenborn.

Mascheck J. (1975), Marcel Duchamp in Perspective, Englewood Cliffs, NJ: Prentice-Hall.

Naumann F. (1993), "Marcel Duchamp: A Reconciliation of Opposites" in De Duve T. (ed.) (1993), The Definitively Unfinished Marcel Duchamp, Cambridge: MIT Press. Von Hantelman D. (2011), "How to do Tings with Art”,The Curatorial Paradigm, n02, p.11-12.

Roberts J. (2007), The Intangibilities of Form, New York: Verso.

Schinckus C. (2018), "Delimitation of flatness in paintings", Art and Perception, Vol. 6, No 1, 67-75.

Tomkins C. (2014): Duchamp: A Biography. New York: The Museum of Modern Art. 